九州大学学術情報リポジトリ

Kyushu University Institutional Repository

\title{
Growth Stimulation of Pediococcus sp. ISK-1 by Sakekasu (Sake Filter Cake) as a Substitute for Mevalonic Acid
}

Herawati, Etmy

Laboratory of Microbial Technology, Department of Food Science and Technology, Faculty of Agriculture, Kyushu University

Ishizaki, Ayaaki

Laboratory of Microbial Technology, Department of Food Science and Technology, Faculty of Agriculture, Kyushu University

https://doi.org/10.5109/24233

出版情報 : 九州大学大学院農学研究院紀要. 42 (3/4)，pp.449-461，1998-03. Kyushu University バージョン：

権利関係: 


\title{
Growth Stimulation of Pediococcus sp. ISK-1 by Sakekasu (Sake Filter Cake) as a Substitute for Mevalonic Acid
}

\author{
Etmy Herawati and Ayaaki Ishizaki \\ Laboratory of Microbial Technology, Department of Food Science and \\ Technology, Faculty of Agriculture, Kyushu University, Hakozaki, \\ Higashi-ku, Fukuoka-shi 812-8581, Japan \\ (Received September 3, 1997 and accepted December 3, 1997)
}

\begin{abstract}
Pediococcus sp. ISK-1, isolated in our laboratory, has been found to inhabit in well-aged Nukadoko which is believed to have lasted for 360 years. We compared the influence of ethanol between Lactobacillus homohiochii JCM $1199^{\mathrm{T}}$ and strain ISK-1 and found that the growth of strain ISK-1 was seriously inhibited by ethanol. However, fermentation of ISK-1 was strongly stimulated by Yamahai-moto Sake and Sakekasu (Sake Filter Cake). Yamahai-moto Sake is obtained from traditional brewing, therefore, it was possible that Sakekasu would have been used for the first Nukadoko preparation at that time. Addition of $8.0 \% \mathrm{NaCl}$ and $2.0 \%$ Sakekasu in MRS broth resulted in substantially improving the cell population and lactate formation. Based on those facts, it is presumed that the first Nukadoko may have been prepared by the supplementation of Sakekasu, Soy souce, and Salt with selective pressure resulting in enrichment of strain ISK-1 of the bacteriocin producer.
\end{abstract}

\section{INTRODUCTION}

Pediococcus sp. ISK-1 was isolated in our laboratory from well-aged Nukadoko which is a rice bran packed fermentation bed for home-made Japanese traditional vegetable pickles (Herawati and Ishizaki, 1997). It is believed that this special Nukadoko, the source of isolation, had first been prepared by Lord Ogasawara, the feudal Lord of Kokura castle (Kitakyushu city) 360 years ago and had lasted until now without spoilage by bacterial contamination. We found that strain ISK-1 produces a new bacteriocin (Kimura et al., 1997), and from this fact we introduce the hypothesis that this compound may have contributed to the long-time preservation of healthy microflora in this Nukadoko. In addition to bacteriocin, strain ISK-1 has very interesting characteristics such as strong arginine hydrolyzing activity, and vigorous oxygen formation from hydrogen peroxide. However, the growth of strain ISK-1 in nutrition medium such as complete medium with glucose (CMG) which consists of yeast extract and polypeptone as nutrition sources was very poor. About $60 \mathrm{~h}$ was needed to consume $30.0 \mathrm{~g} / \mathrm{l}$ glucose at a cell density of approximately $4.5 \mathrm{~g} / \mathrm{l}$. It is, therefore, a question of how Lord Ogasawara had made the first Nukadoko to stimulate the growth of strain ISK-1 among other microorganisms inhabiting the environment. The special medium ingredient prepared by Lord Ogasawara at that time may provide the selective pressure of the screening of strain ISK-1 resulting in long-time preservation with ideal microflora in his Nukadoko. However, we cannot confirm this hypothesis because he did not leave any record of his experimental work.

In a previous paper, we found that D-mevalonic acid (MVA) strongly stimulated the growth of strain ISK-1 (Herawati and Ishizaki, 1997). Mevalonic acid the first found by 
Tamura from Koji as hiochic acid (Tamura, 1956; Tamura, 1978; Tamura, 1994) and at almost the same time Skeggs et al. (1956) and Wright et al. (1956) reported isolation of mevalonic acid as a new acetate replacing factor. Tamura and Folkers (1957) then confirmed that hiochic acid and mevalonic acid were the same compound. The effect of MVA on the growth of a lactic acid microorganism was first reported by Kitahara et al (1957a and 1957b) on Lactobacillus homohiochii isolated from Sake (Kitahara et al., $1957 \mathrm{a} ; 1957 \mathrm{~b})$. However, it is absolutely certain that no information on MVA was available in the Lord's time. We therefore presumed that the Lord used Sakekasu (Sake Filter Cake=SFC) as a substitute material to supply MVA for his first Nukadoko preparation. In his time, the Sake (Japanese rice wine) brewing process was a conventional one in which lactic acid fermentation was produced concomitantly by natural microflora (Yamahai-moto starter). In modern Sake brewing, pure lactic acid is added before vigorous alcohol fermentation for rapid brewing and proper process control to avoid contamination.

This paper deals with the stimulative effect of Sakekasu for the culture of Pediococcus sp. ISK-1, as a substitute for MVA. Also, the growth of strain ISK-1 was stimulated by Sake brewed by Yamahai-moto. Based on these observations, we can presume that the old Nukadoko was prepared by a special recipe for a medium using Sakekasu from the traditional Sake brewing process (Yamahai-moto ).

\section{MATERIALS AND METHODS}

\section{Microorganism}

The microorganism used in this study was a bacteriocin producer (Kimura et al., 1997), Pediococcus sp. ISK-1, isolated from well-aged Nukadoko preserved by Mrs. Teruko Sato in Kokura-ku, Kitakyushu city (it is believed that the originator of this Nukadoko is Lord Ogasawara) and stored in a deep-freeze refrigerator $\left(-80^{\circ} \mathrm{C}\right)$. The microorganisms were grown at $37^{\circ} \mathrm{C}$ for $18 \mathrm{~h}$ in thioglycollate (TGC) medium (Difco Laboratories, Detroit, Mich.,) autoclaved at $121^{\circ} \mathrm{C}$ for $15 \mathrm{~min}$. for rejuvenation. Lactobacillus homohiochii JCM $1199^{\mathrm{T}}$ was purchased from the Japan Collection of Microorganisms (JCM), (Riken Wako, Saitama), and was grown at $30^{\circ} \mathrm{C}$ for $20 \mathrm{~h}$ in Sake medium.

\section{Medium}

The complete medium with glucose (CMG) used for flask culture was the same as that previously described (Herawati and Ishizaki, 1997). The basal medium for jar fermentation was MRS (deMan, Rogosa, and Sharpe) broth using 3.0\% initial glucose. Synthetic medium was prepared according to the method described previously (Herawati and Ishizaki, 1997). The medium for Lactobacillus homohiochii JCM $1199^{\mathrm{T}}$ consisted of Sake (Fukutokucho Yamahai-moto, Fukutokucho Co., Ltd., Kurume, Fukuoka) $700 \mathrm{ml}$, yeast extract (Difco Laboratories, Detroit, Mich.,) $5 \mathrm{~g}$, liver extract concentrate (SIGMA Chemical Co., St. Louis, MO) $0.2 \mathrm{~g}$ and deionized water $100 \mathrm{ml}$. The $\mathrm{pH}$ of the medium was adjusted to 5.4 , and the medium was autoclaved at $105^{\circ} \mathrm{C}$ for $10 \mathrm{~min}$.

Sake used in this experiment is Fukutokucho Ginjoshu and Fukutokucho Yamahai-moto (brewed by Yamahai starter described above), a gift from Fukutokucho 
Co., Ltd. (Kurume, Fukuoka), Gold prize (in a new brewed Sake contest for fiscal 1996) Ginjoshu, a gift from the Office of Brewing Technology, Fukuoka Regional Taxation Bureau, (Fukuoka) and Kizakura (Kizakura Brewing Co., Kyoto), purchased from a local Sake shop in Fukuoka. Sakekasu (cake discharged from the filter press in Sake filtration) of Fukutokucho Yamahai-moto is a gift from Fukutokucho Co., Ltd. (Kurume, Fukuoka). The dry matter content of Sakekasu was 37.7\%. Mieki is a gift from Ajinomoto Co., Ltd. (Tokyo). ( \pm ) Mevalonic lactone (97\%) was purchased from Aldrich Chem. Co., (Milw. WI).

\section{Culture method}

The culture method for the flask and jar cultures was the same as that described in the previous paper (Herawati and Ishizaki, 1997).

\section{Bioassay}

The medium for the bioassay of MVA by Lactobacillus homohiochii JCM $1199^{\top}$ has been established by Tamura et al. (1968). However we simplified the medium composition based on the medium for Lactobacillus homohiochii given by JCM catalogue (1992) and obtained satisfactory result and good reproductivity. The bioassay medium for Lactobacillus homohiochii JCM $1199^{\mathrm{T}}$ consisted of 8 parts of solution A and 2 parts of solution B. Solution A, the basal medium, consisted of casein peptone, tryptic digest (BBL, Becton Dickinson Microbiology Systems, Cockeysville, MD) $10 \mathrm{~g}$, yeast extract (Difco Laboratories, Detroit, Mich.) $5 \mathrm{~g}$, meat extract (Kyokuto Seiyaku Co., Tokyo) $2 \mathrm{~g}$, glucose $20 \mathrm{~g}, \mathrm{KH}_{2} \mathrm{PO}_{4} 0.5 \mathrm{~g}, \mathrm{~K}_{2} \mathrm{HPO}_{4} 0.5 \mathrm{~g}, \mathrm{FeSO}_{4} \cdot 7 \mathrm{H}_{2} \mathrm{O} 10 \mathrm{mg}, \mathrm{MgSO}_{4} \cdot 7 \mathrm{H}_{2} \mathrm{O}$ $0.2 \mathrm{~g}, \mathrm{MnSO}_{4} \cdot \mathrm{xH}_{2} \mathrm{O} 7.5 \mathrm{mg}$, Tween $801 \mathrm{ml}$, ethanol $40 \mathrm{ml}$, and sodium acetate $20 \mathrm{~g}$, in $800 \mathrm{~m} l$ of deionized water. Solution $\mathrm{B}$, standard and samples, was prepared as follows. In the case of MVA, $30 \mathrm{mg}$ of ( \pm ) mevalonic lactone was dissolved in $200 \mathrm{ml}$ deionized water. $1,2,3,4$, and $5 \mathrm{ml}$ of this solution were then mixed with $9,8,7,6$, and $5 \mathrm{ml}$ of deionized water, respectively. In the case of Sake, $10 \mathrm{ml}$ of Yamahai-moto Sake was used and filled to $100 \mathrm{~m} l$ with deionized water. Then $1,2,3,4$, and $5 \mathrm{~m} l$ of this Sake solution were mixed with $9,8,7,6$, and $5 \mathrm{ml}$ of deionized water, respectively. In the case of Sakekasu, $10 \mathrm{~g}$ of Sakekasu was weighed and dissolved into $80 \mathrm{ml}$ of deionized water. The suspended solid material in the Sakekasu solution was then removed by filtration using Advantec 1011 filter paper $125 \mathrm{~mm} \varnothing$ (Toyo Roshi Kaisha, Ltd., Tokyo), and the filtrate was filled to $100 \mathrm{ml}$. Then 1,2, 3, 4, and $5 \mathrm{ml}$ of Sakekasu solution were mixed with $9,8,7,6$, and $5 \mathrm{~m} l$ of deionized water respectively. Eight parts of solution $\mathrm{A}$ and 2 parts of solution $\mathrm{B}$ were mixed and the $\mathrm{pH}$ of the mixture was adjusted to 5.2. The mixture was subjected to autoclaving at $105^{\circ} \mathrm{C}$ for $10 \mathrm{~min}$. Fifty $\mu l$ of Lactobacillus homohiochii JCM $1199^{\mathrm{T}}$ precultured by Sake medium was inoculated and cultured at $30^{\circ} \mathrm{C}$ for $65 \mathrm{~h}$. Growth of the microorganism in individual test tubes was measured by the optical absorbance at $562 \mathrm{~nm}$ with a spectrophotometer (UVIDEC 320 JAS Co., Tokyo).

The medium for bioassay of MVA for Pediococcus sp. ISK-1 was the same as the medium for Lactobacillus homohiochii JCM $1199^{\mathrm{T}}$ except for the omission of ethanol, Tween 80 and sodium acetate in solution A. In Tamura's medium, acetate was used to increase buffer capacity (Tamura et al., 1968), and at the same time, we presume that it was taking into account that MVA was found as a acetate-replacing factor (Wright et al., 
1956). Strain ISK-1, however, produced acetic acid as by product and it inhibited the growth of strain ISK-1 (data not shown). Thus, we omitted acetate from the bioassay medium for strain ISK-1. Fifty $\mu l$ of strain ISK-1 precultured by TGC medium was inoculated and cultured at $37^{\circ} \mathrm{C}$ for $65 \mathrm{~h}$. Growth of the microorganism in individual test tubes was measured. The increase in absorption for both microorganisms, $L$. homohiochii JCM $1199^{\top}$ and strain ISK-1, was linear relative to the standard MVA concentration and the MVA activity in Sake and Sakekasu.

\section{Analysis}

The cell density of the broth and the concentrations of L-lactate, DL-lactate, and glucose were measured by the same method described previously (Herawati and Ishizaki., 1997).

\section{RESULTS}

\section{Influence of ethanol on fermentation of Pediococcus sp. ISK-1}

The influence of ethanol on strain ISK-1 was investigated. The basal medium used in this experiment was the synthetic medium (Herawati and Ishizaki, 1997). Ethanol (99.5\%) was added to the autoclaved basal medium aseptically through a syringe with DISMIC-25 (Toyo Roshi Co., Ltd., Tokyo). The result is shown in Fig. 1. As shown in this figure, ethanol seriously inhibited the fermentation of strain ISK-1 and the fermentation was not entirely observed with $10.0 \%(\mathrm{v} / \mathrm{v})$ ethanol. Because the fermentation of Lactobacillus homohiochii is stimulated by ethanol (Tamura, 1978; Tamura, 1994), the fermentation characteristics of strain ISK-1 are not the same as those of $L$. homohiochii JCM $1199^{\mathrm{T}}$.

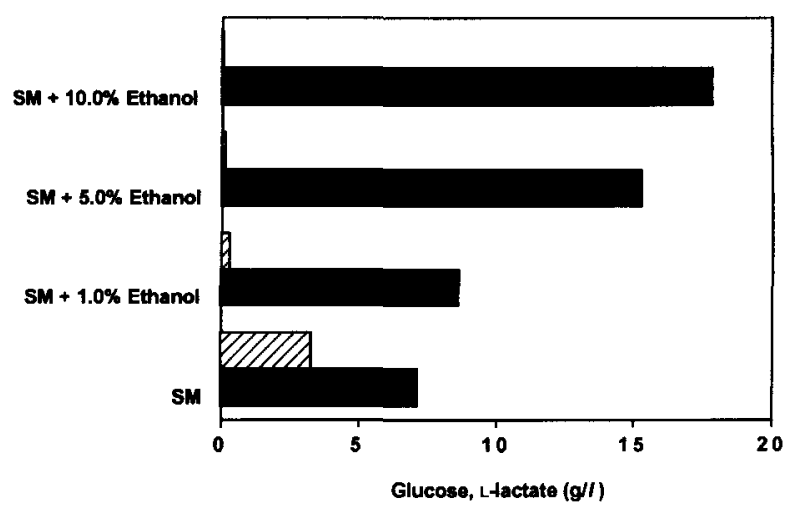

Fig. 1. Effect of Ethanol Supplementation in Synthetic Medium (SM) on Lactate Fermentation Using Pediococcus sp. ISK-1 in Flask Culture at $24 \mathrm{~h}$.

Glucose consumption , L-lactate production ( 


\section{Stimulative effect of Yamahai-moto Sake on fermentation of Pediococcus sp. ISK-1}

The effect of Yamahai-moto Sake which may contain various amino acids from rice protein and MVA on the growth of strain ISK-1 was investigated. Fig. 2 shows the results of the experiment using a synthetic medium as the basal medium. As shown in this figure, Yamahai-moto Sake stimulated the fermentation of strain ISK-1 in spite of the ethanol contained in the Sake. To observe the effect of amino acid on the fermentation of strain ISK-1, 5.0\% Mieki was added. Mieki strongly stimulated the fermentation, however, the effect of Yamahai-moto Sake (10.0\%) was slightly greater than that of Mieki $(5.0 \%)$. Taking into account the inhibitory effect of the ethanol existing in Sake, the stimulative effect of Yamahai-moto Sake may be due to the MVA contained in Sake. The same result was obtained in an experiment using CMG as the basal medium (Fig. 3). As shown in Fig. 3, the fermentation using CMG +5.0\% Mieki+10.0 ppm MVA was better than the fermentation using the medium containing $10.0 \%$ Yamahai-moto Sake in place of $10.0 \mathrm{ppm}$ MVA. This may be due to the ethanol contained in Sake.

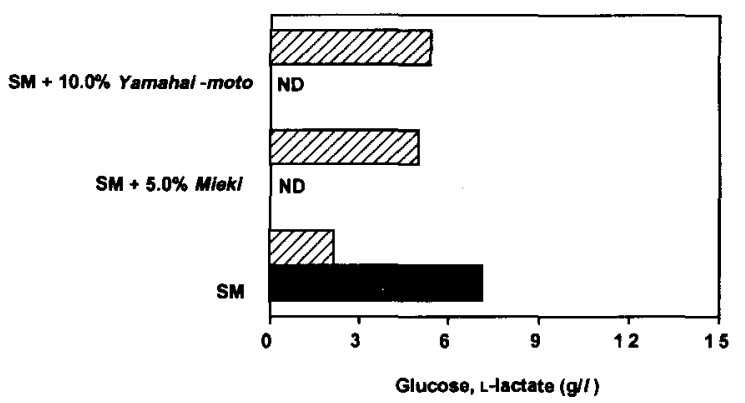

Fig. 2. Effect of Mieki and Yamahai-moto Sake Supplementation in SM on Lactate Fermentation Using Pediococcus sp. ISK-1 in Flask Culture at $24 \mathrm{~h}$.

Symbols sre the same as in Fig. 1.

ND : not detected.

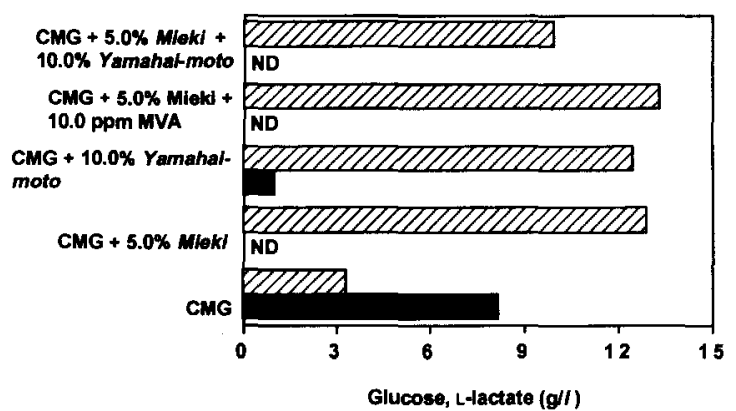

Fig. 3. Effect of Mieki, MVA and Yamahai-moto Sake Supplementation in CMG Medium on Lactate Fermentation Using Pediococcus sp. ISK-1 in Flask Culture at $24 \mathrm{~h}$.

Symbols are the same as in Fig. 1.

ND : not detected. 
Evaluation of the activity equivalent to mevalonic acid contained in Sake and Sakekasu by bioassay employing Lactobacillus homohiochi JCM 1199' and Strain ISK-1

The growth of $L$. homohiochii JCM $1199^{\mathrm{T}}$ and strain ISK-1 at MVA concentrations of $3,6,9,12$, and $15 \mathrm{ppm}$ was measured as a standard. The results are shown in Fig. 7 . From the result, relationship between the OD (optical density) of L. homohiochii JCM $1199^{\mathrm{T}}$ and the MVA concentration (Xm ppm) was expressed as :

$(\mathrm{OD})_{\mathrm{h}}=0.260+2.667 \times 10^{-2} \mathrm{Xm}\left(\mathrm{r}^{2}=1.000\right)($ Fig. $7 \mathrm{a})$

while that of strain ISK-1 was

$$
(\mathrm{OD})_{\mathrm{P}}=0.520+6.667 \times 10^{-3} \mathrm{Xm}\left(\mathrm{r}^{2}=1.000\right)(\text { Fig. } 7 \mathrm{~b})
$$

where (OD $)_{\mathrm{h}}$ is the OD of L.homohiochii JCM $1199^{\mathrm{T}}$, (OD) $)_{\mathrm{p}}$ is the OD of Pediococcus sp. ISK-1 and $\mathrm{r}^{2}$ is a regression coefficient. Thus, the MVA unknown concentration can be determined from the OD value by the relationship for L. homohiochii JCM $1199^{\mathrm{T}}$

$\mathrm{Xm}=\left\{(\mathrm{OD})_{\mathrm{h}}-0.260\right\} / 0.027$

and for strain ISK-1

$\mathrm{Xm}=\left\{(\mathrm{OD})_{\mathrm{F}}-0.520\right\} / 0.007$.

Fig. 8. shows the results of the bioassay for Sake. The relationship between the OD

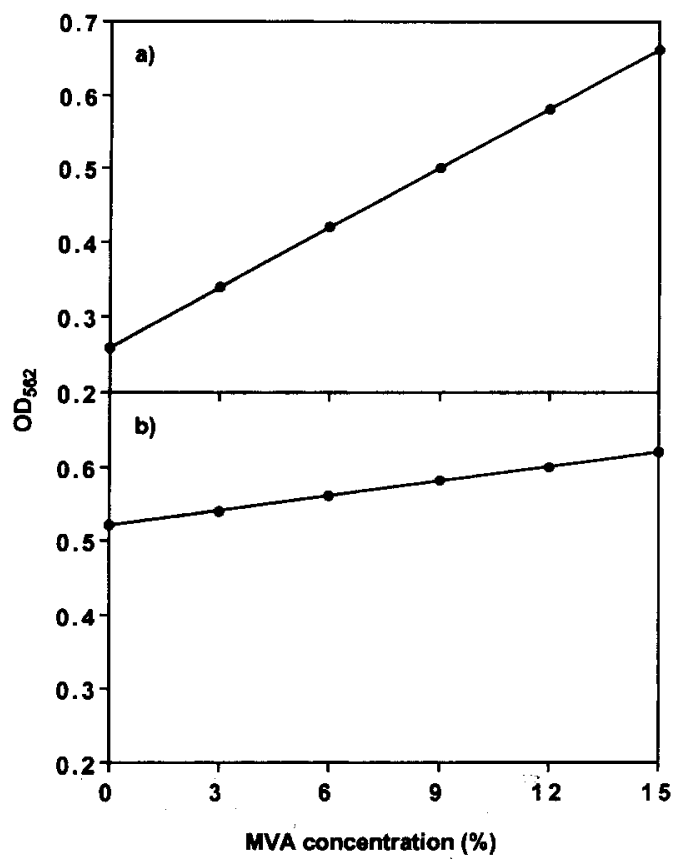

Fig. 7. Relationship between MVA Concentration and Growth of Lactobacillus homohiochii JCM $1199^{\mathrm{T}}$ (a) and Pediococcus sp. ISK-1 (b). 
to prevent contamination during Sake brewing. We presume that this forms a high MVA concentration in Sake so that Yamahai-moto Sake stimulates the fermentation of strain ISK-1.

However, it is suspicious that the different result observed among three brands may be due to different technology of individual brewer. Thus another experiment has been carried out that Ginjoshu of Fukutokucho and Yamahai-moto of Fukutokucho were compared at the same culture condition. Results are shown in Fig. 5. According to the results, it is clear that Yamahai-moto Sake gave excellent result. Yamahai-moto Sake may contain strong growth promotor than the one of Ginjoshu which is from ordinary brewing process.

\section{Effect of Sakekasu (Sake Filter Cake)}

From the results stated above, it is assumed Yamahai-moto Sake contains a high concentration of MVA. This suggests that Sakekasu must be a good source of MVA. Sakekasu from Yamahai-moto brewing, a gift from Fukutokucho Co., Ltd., was used to confirm this hypothesis. The results are shown in Fig. 6. From this figure, Sakekasu is observed to stimulate the fermentation of strain ISK-1 with an increase in Sakekasu concentration for both CMG and bioassay medium in which ethanol, Tween 80 and sodium acetate were omitted.

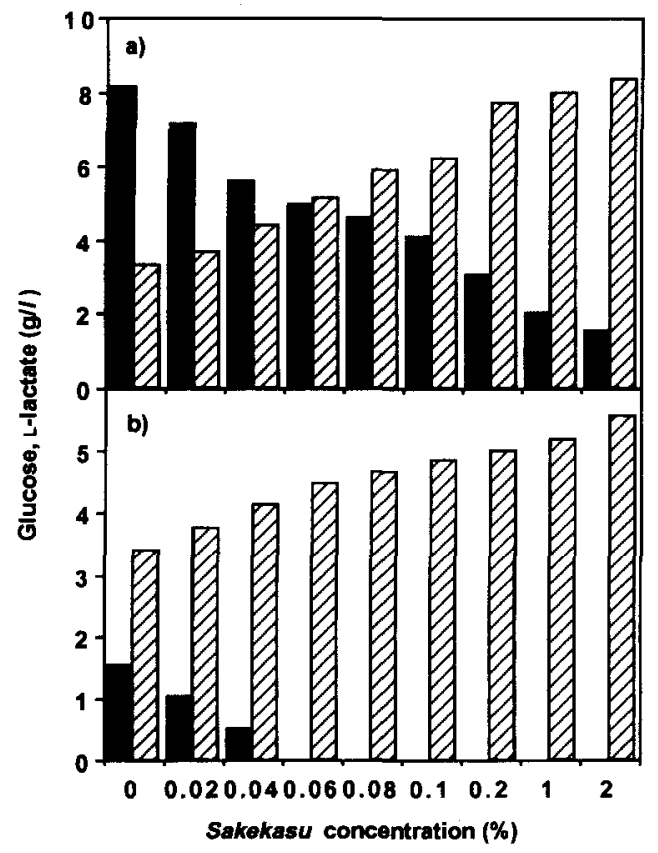

Fig. 6. Effect of Sakekasu Supplementation in CMG (a) and SM (b) on Lactate Fermentation Using Pediococcus sp. ISK-1 in Flask Culture at $24 \mathrm{~h}$.

Symbols are the same as in Fig. 1. 


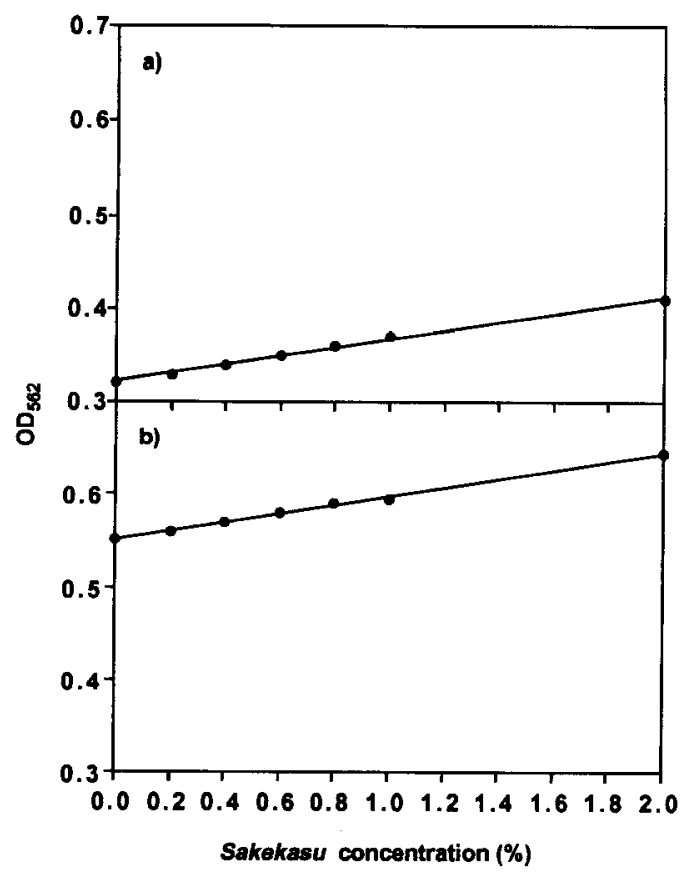

Fig. 9. Relationship between Sakekasu Concentration and Growth of Lactobacillus homohiochii JCM $1199^{\mathrm{T}}$ (a) and Pediococcus sp. ISK-1 (b).

stronger than that on L. homohiochii JCM $1199^{\mathrm{T}}$.

\section{Effect of Sakekasu on MRS medium}

Strain ISK-1 can grow very well on an MRS medium (Kimura et al., 1997). The effect of Sakekasu on MRS medium was investigated. As shown in Fig. 10, a high $\mathrm{NaCl}$ concentration $(8.0 \%)$ stimulated lactate formation. With a high $\mathrm{NaCl}$ concentration in MRS, Sakekasu increased the lactate formation in accordance with the increase in Sakekasu concentration.

\section{Jar culture test}

To confirm the results obtained in the flask culture tests, we performed a jar culture experiment at a regulated $\mathrm{pH}$. The results are shown in Fig. 11. Addition of $8.0 \% \mathrm{NaCl}$ and $2.0 \%$ Sakekasu to MRS medium containing 3.0\% glucose (control medium) is shown to stimulate cell population tremendously and to reduce fermentation time to the control medium. 


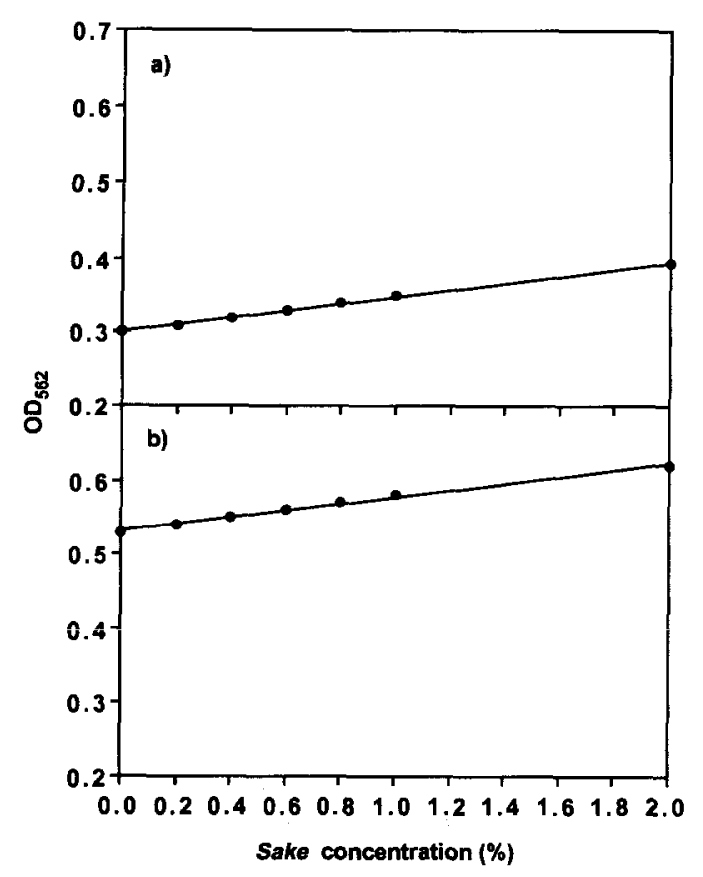

Fig. 8. Relationship between Sake Concentration and Growth of Lactobacillus homohiochii JCM $1199^{\mathrm{T}}$ (a) and Pediococous sp. ISK-1 (b).

of the microorganism and the Sake concentration (Xs \%) was expressed as :

$(\mathrm{OD})_{\mathrm{h}}=0.301+4.755 \times 10^{-2} \mathrm{Xs}\left(\mathrm{r}^{2}=0.999\right)$

for L. homohiochii JCM $1199^{\mathrm{T}}$ (Fig. 8a) and

$(\mathrm{OD})_{\mathrm{p}}=0.532+4.511 \times 10^{-2} \mathrm{Xs}\left(\mathrm{r}^{2}=0.996\right)$

for strain ISK-1 (Fig. 8b).

Therefore, the MVA concentration equivalent in Sake, (MVA) $)_{\mathrm{seq}}$, can be estimated by the relationship in which $1.0 \%$ Sake $=1.8 \mathrm{ppm}(\mathrm{MVA})_{\text {seq }}$ for $L$. homohiochii $\mathrm{JCM} 1199^{\mathrm{T}}$ but $6.8 \mathrm{ppm}(\mathrm{MVA})_{\mathrm{seq}}$ for strain ISK-1.

Fig. 9. shows the results of the bioassay for Sakekasu. The relationship between the $\mathrm{OD}$ of the microorganism and the Sakekasu concentration (Xk\%) was expressed as :

$(\mathrm{OD})_{\mathrm{h}}=0.322+4.522 \times 10^{-2} \mathrm{Xk}\left(\mathrm{r}^{2}=0.996\right)$

for L. homohiochii JCM $1199^{\mathrm{T}}$ (Fig. 9a) and

$(\mathrm{OD})_{\mathrm{p}}=0.551+4.701 \times 10^{-2} \mathrm{Xk}\left(\mathrm{r}^{2}=0.998\right)$ for strain ISK-1 (Fig. 9b).

Therefore, the MVA concentration equivalent in Sakekasu, (MVA) keq, can be estimated by the relationship in which $1.0 \%$ Sakekasu $=1.7 \mathrm{ppm}(\mathrm{MVA})_{\mathrm{keq}}$ for $L$. homohiohii JCM $1199^{\mathrm{T}}$ but $7.1 \mathrm{ppm}$ (MVA) keq $_{\text {for strain ISK-1. }}$

Based on this fact, the MVA concentration in Sake can be said to be almost the same as that in Sakekasu. The MVA activity on strain ISK-1 is also said to be 4 times 


\section{DISCUSSION}

Pediococcus sp. ISK-1 was isolated from well-aged Nukadoko which is believed to have been first prepared by Lord Ogasawara 360 years ago. Strain ISK-1 has very interesting characteristics in addition to producing a novel bacteriocin. There are a few other well-aged Nukadokos in Kokura and Fukuoka (Northern Kyushu territory) area and all those Nukadokos are believed to be originated by Lord Ogasawara. This is, however, a spread wide story among citizens without any scientific proof. However, it is a fact that these Nukadokos have been inoculated and transfered for many generations because we can prove it by the owner's word. We presume that the bacteriocin produced by the microorganism inhabiting this Nukadoko has the function of maintaining ideal microflora in the well-aged Nukadoko. Our next question was how the first Nukadoko was prepared to enrich the bacteriocin producer among the natural microflora. Lord Ogasawara did not leave any record of his experiment, so it is impossible to confirm his method from scientific records. However, as mentioned in this paper, we found that MVA or MVA equivalent activity stimulated tremendously the fermentation of strain ISK-1. In addition, the strong activity of this compound has been confirmed in Sake and Sakekasu, and very strong activity was observed in Sakekasu from a traditional Sake brewing process (Yamahai-moto). Mevalonic acid was first found as hiochic acid by Tamura $(1956 ; 1978 ; 1994)$ from Koji, and it was presumed that hiochic acid in Sake came from Koji. However, Wright et al. (1956) isolated MVA from distillers dried soluble from whiskey distiller where no koji was used. Tamura survayed the microorganism for fermentative production of MVA and found that lactic acid bacteria produced MVA (Wagner and Folkers, 1961; Tamura, 1994). We, therefore, presumed that lactic acid bacteria working in Yamahai process produced MVA thus Yamahai-moto Sake gave strong growth promoting effect on strain ISK-1. Because the Yamahai-moto process is the traditional method for Sake brewing, it is certain that, in the Lord's time, Sake and Sakekasu from the traditional Yamahai-moto brewing process were available. Considering that strain ISK-1 is sensitive to ethanol, it is presumed that Lord Ogasawara used Sakekasu but not Sake for his Nukadoko preparation. In addition to MVA, the fermentation of strain ISK-1 was stimulated by Mieki and $\mathrm{NaCl}$. Mieki is a soybean protein hydrolyzate; therefore, this is very similar to the traditional fermented soy sauce. Based on those facts, we can imagine that the first Nukadoko was prepared using rice bran (nuka) mixed with Sakekasu, Shoyu (traditional fermented soy sauce), and salt. This composition may provide the selective pressure applied by the Lord to form the ideal microflora for good quality Nukadoko. We isolated another bacteriocin producer from other well-aged Nukadokos which are also believed to originate from Lord Ogasawara but have been preserved by other persons. The characteristics and similarity of this new strain compared to strain ISK-1 are now under investigation.

\section{REFERENCES}

Anonymous 1992 In "Catalogue of strains, Fifth Edition, media No. 21, Lactobacillus medium III, Japan Collection of Microorganisms (JCM), Saitama., 396

Herawati, E., and A. Ishizaki 1997 Optimization of the culture medium for growth and the kinetics of lactate fermentation by Pediococcus sp. ISK-1. Biosci. Biochem. Biotech., 61: 604-608 


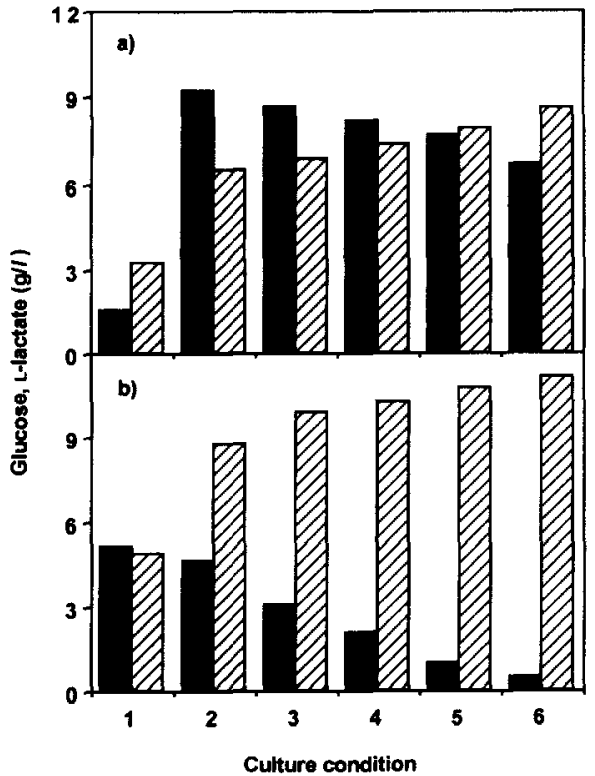

Fig. 10. Effect of Sakekasu and NaCl Supplementation in SM (a) and MRS Medium (b) on Lactate Fermentation Using Pediococcus sp. ISK-1 in Flask Culture at $24 \mathrm{~h}$.

Culture condition :

(1) Control (CTR) for SM (a) and MRS (b), (2) CTR+8.0\% NaCl, (3) $\mathrm{CTR}+8.0 \% \mathrm{NaCl}+0.1 \%$ Sakekasu, (4) CTR $+8.0 \% \mathrm{NaCl}+0.2 \%$ Sakekasu, (5) CTR $+8.0 \% \mathrm{NaCl}+1.0 \%$ Sakekasu, (6) $\mathrm{CTR}+8.0 \%$ $\mathrm{NaCl}+2.0 \%$ Sakekasu

Symbols are the same as in Fig.1.

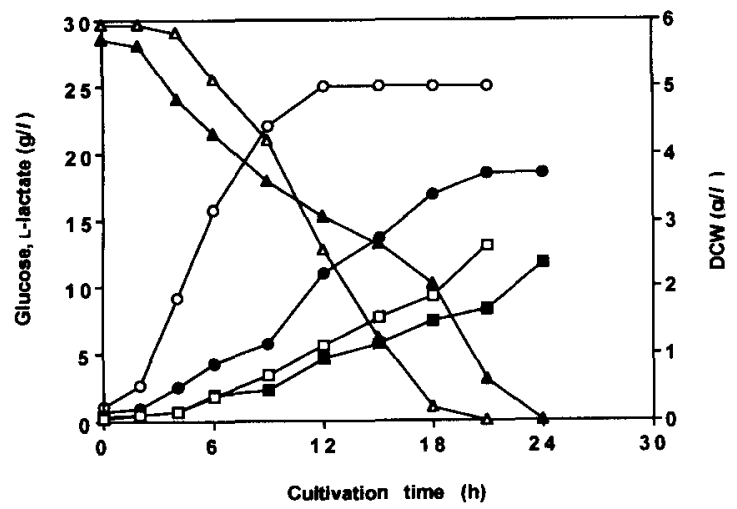

Fig. 11. Comparation of the Growth (DCW), Glucose Consumption and LLactate Production of Pediococcus sp. ISK-1 in Jar Culture.

DCW $(--\bigcirc)$, glucose consumption $(-\triangle \triangle)$, L-lactate production (- $-\square$ ). Closed symbol is MRS medium, open symbol is MRS $+8.0 \% \mathrm{NaCl}+2.0 \%$ Sakekasu. 


\section{DISCUSSION}

Pediococcus sp. ISK-1 was isolated from well-aged Nukadoko which is believed to have been first prepared by Lord Ogasawara 360 years ago. Strain ISK-1 has very interesting characteristics in addition to producing a novel bacteriocin. There are a few other well-aged Nukadokos in Kokura and Fukuoka (Northern Kyushu territory) area and all those Nukadokos are believed to be originated by Lord Ogasawara. This is, however, a spread wide story among citizens without any scientific proof. However, it is a fact that these Nukadokos have been inoculated and transfered for many generations because we can prove it by the owner's word. We presume that the bacteriocin produced by the microorganism inhabiting this Nukadoko has the function of maintaining ideal microflora in the well-aged Nukadoko. Our next question was how the first Nukadoko was prepared to enrich the bacteriocin producer among the natural microflora. Lord Ogasawara did not leave any record of his experiment, so it is impossible to confirm his method from scientific records. However, as mentioned in this paper, we found that MVA or MVA equivalent activity stimulated tremendously the fermentation of strain ISK-1. In addition, the strong activity of this compound has been confirmed in Sake and Sakekasu, and very strong activity was observed in Sakekasu from a traditional Sake brewing process (Yamahai-moto). Mevalonic acid was first found as hiochic acid by Tamura $(1956 ; 1978 ; 1994)$ from Koji, and it was presumed that hiochic acid in Sake came from Koji. However, Wright et al. (1956) isolated MVA from distillers dried soluble from whiskey distiller where no koji was used. Tamura survayed the microorganism for fermentative production of MVA and found that lactic acid bacteria produced MVA (Wagner and Folkers, 1961; Tamura, 1994). We, therefore, presumed that lactic acid bacteria working in Yamahai process produced MVA thus Yamahai-moto Sake gave strong growth promoting effect on strain ISK-1. Because the Yamahai-moto process is the traditional method for Sake brewing, it is certain that, in the Lord's time, Sake and Sakekasu from the traditional Yamahai-moto brewing process were available. Considering that strain ISK-1 is sensitive to ethanol, it is presumed that Lord Ogasawara used Sakekasu but not Sake for his Nukadoko preparation. In addition to MVA, the fermentation of strain ISK-1 was stimulated by Mieki and $\mathrm{NaCl}$. Mieki is a soybean protein hydrolyzate; therefore, this is very similar to the traditional fermented soy sauce. Based on those facts, we can imagine that the first Nukadoko was prepared using rice bran (nuka) mixed with Sakekasu, Shoyu (traditional fermented soy sauce), and salt. This composition may provide the selective pressure applied by the Lord to form the ideal microflora for good quality Nukadoko. We isolated another bacteriocin producer from other well-aged Nukadokos which are also believed to originate from Lord Ogasawara but have been preserved by other persons. The characteristics and similarity of this new strain compared to strain ISK-1 are now under investigation.

\section{REFERENCES}

Anonymous 1992 In "Catalogue of strains, Fifth Edition, media No. 21, Lactobacillus medium III, Japan Collection of Microorganisms (JCM), Saitama., 396

Herawati, E., and A. Ishizaki 1997 Optimization of the culture medium for growth and the kinetics of lactate fermentation by Pediococcus sp. ISK-1. Biosci. Biochem. Biotech., 61: 604-608 
Kinura, H., R. Nagano, K. Sonomoto, and A. Ishizaki 1997 A bacteriocin of strain Pediococcus sp. ISKK-1 isolated from Nukadoko, bed of fermented rice bran. Biosci. Biochem. Biotech., 61: 1049-1051

Kitahara, K., T. Kaneko, and O. Goto 1957a Taxonomic studies on the hiochi-bacteria, specific saprophytes of sake. İ. İsolation and grouping of bacteriocin strains. J. Gen. Appl. Microbiol., $\overline{\mathbf{3}}$ : 102110

Kitahara, K, T. Kaneko, and O. Goto $1957 \mathrm{~b}$ Taxonomic studies on the hiochi-bacteria, specific saprophytes of sake. II. Identification and clasification of hiochi-bacteria. J. Gen. Appl. Microbiol., 3: $111-120$

Skeggs, H. R., L. D. Wright, E. L. Cresson, G. D. E. MacRae, C. H. Hoffman, D. E. Wolf, and K. Folkers 1956 J. Bacteriol, 72: 519

Tamura, G 1956 Hiochic acid, a new growth factor for Lactobacillus homohiochi and Lactobacillus heterohiochi. J. Gen. Appl. Microbiol., 2: 431-434

Tamura, G., and K. Folkers 1957 Identify of mevalonic and hiochic acid. J. Org. Chem., 23: 772

Tamura, G., K. Ando, K. Kodama, and K. Arima 1968 Production of mevalonic acid by fermentation. Appl. Microbiol., 16: $965-972$

Tamura, G 1978 Hiochi kin hatsuiku inshi no hatten oyobi kanren shokenkyu, Nippon Nogei Kagaku Kaishi. 52: R179-R190 (in Japanese)

Tamura, G 1994 Hiochi san kara kouji kin no bunshi ikushu he, Nippon Joso Kyokaishi., 89: 793-804 (in Japanese)

Wagner, A. F., and K. Folkers 1961 Discovery and chemistry of mevalonic acid. Adv. in Enzymol., 23: 473

Wright, L. D., E. L. Cresson, H. R. Skeggs, G. D. E. MacRae, C. H. Hoffman, D. E. Wolf, and K. Folkers 1956 Isolation of a new acetate replacing factor. J. Am. Chem. Soc., 78: 5273-5275 